\title{
The efficiency of biomass removal from model woodworking wastewater with polyethylenimine
}

\author{
Sanita Vitolina ${ }^{\mathrm{a}}$, Galia Shulga ${ }^{\mathrm{a}}$, Brigita Neiberte ${ }^{\mathrm{a}}$, Sandra Livcha ${ }^{\mathrm{a}}$, Anrijs Verovkins ${ }^{\mathrm{a}}$, \\ Maris Puke ${ }^{a}$, Skaidrite Reihmane ${ }^{b}$ \\ ${ }^{a}$ Latvian State Institute of Wood Chemistry, 27 Dzerbenes Str., Riga, LV-1006, Latvia \\ ${ }^{b}$ Riga Technical University, Faculty of Material Science And Applied Chemistry, 14/24 Azenes Str., Riga, LV-1048, Latvia
}

\begin{abstract}
The production of veneer in Latvia and many countries of Eastern Europe is accomplished by the hydrothermal treatment of hardwood in special water basins. As a result, formed effluents contain wood-originated pollutants which are responsible for the enhanced chemical oxygen demand and the intensive color of the wastewater. Keeping in mind the zero waste policy for rational use of bioresources and the possible usage of waste wood originated matter in practice, it is very important to extract the formed biomass from the basin's wastewater. In this work, for imitating woodworking wastewater, birch sawdust was hydrothermally treated in mild alkaline conditions at $90^{\circ} \mathrm{C}$. The yield of the solid biomass did not exceed $7 \%$ and contained, mainly, hemicelluloses in the polysaccharide form and lignin. The applied instrumental analysis methods (FTIR and UV-spectroscopy, HLPC, ${ }^{13} \mathrm{C}-\mathrm{NMR}$ ) testify the dominant content of hemicelluloses in the obtained biomass. The results of fractionation of the biomass have indicated that the content of lignin, hemicelluloses and watersoluble degraded wood products in the solid biomass corresponds to the following mass ratio: 1.2/6.7/1.0, respectively.

The effectiveness of the isolation of wood biomass from the hydrolysate with polyethyleneimine (PEI) was studied. In coagulationflocculation process using single coagulant, coagulant dosage and $\mathrm{pH}$ plays an important role in determining the coagulation efficiency. At the optimum PEI dosage of $35 \mathrm{mg} / \mathrm{L}$ and optimum $\mathrm{pH}$ of 6.0 , total biomass removal was determined to be $93 \%$ (1302 $\mathrm{mg} / \mathrm{L})$, lignin removal is $64 \%$, PI and color reduction is $57 \%$ and $90 \%$, respectively. Compared with the widely used polyaluminum chloride (PACl) coagulant, PEI is characterized by higher indices of the removal of total biomass and lignin, as well as color and PI at the application dose 2.8 times lower than that for the $\mathrm{PACl}$.
\end{abstract}

Keywords: hydrothermal treatment; wastewater; biomass; coagulation.

\section{Introduction}

Biomass pre-treatment, directed to the destruction of the lignocellulosic matrix, occupies a leading position in lignocellulosic biorefinery for obtaining biofuels and chemicals from cellulose, hemicelluloses and lignin [1-3]. The production of veneer in Latvia and many countries of Eastern Europe is accomplished by the hydrothermal treatment of hardwood in special water basins for $16-18 \mathrm{~h}$ at a temperature of approximately $50^{\circ} \mathrm{C}$ and in a normal pressure circumstances [4]. Depending on the conditions of the hydrothermal treatment a different yield of wood hydrolysis products occurs due to the hydrolysis of the lignocellulosic matrix [5]. As a result, the formed effluents are polluted with lignin, hemicelluloses, extractives and degraded products from these wood substances which are responsible for the enhanced chemical oxygen demand and the intensive color of the wastewater. The chemical indexes of the effluents depend on many factors, namely, the wood species, temperature, $\mathrm{pH}$, etc. Keeping in mind the volume of the polluted effluents formed annually and the zero waste policy for rational use of bioresources, it is very important to extract the formed biomass from the effluents efficiently to achieve more rational utilization than the dilution with pure water to maximum allowable concentrations and discharging to natural water basins. It is known that sewage sludge can be used successfully for soil improvement [6] and for producing building materials [7] and sorbents [8]. Besides, the effective removing of biomass from the wastewater will allow returning the purified wastewater in the basic technological cycle. The reagent method of pollutants' isolation based on the coagulation and flocculation of colloidal particles is widely used in wastewater treatment. The most known coagulants/flocculants are represented by multivalent inorganic metal salts (mainly aluminum and ferric

Corresponding author: Sanita Vitolina. E-mail address: sanita.vitolina@gmail.com

http://dx.doi.org/10.3846/enviro.2014.067

(C) 2014 The Authors. Published by VGTU Press. This is an open-access article distributed under the terms of the Creative Commons Attribution License, which permits unrestricted use, distribution, and reproduction in any medium, provided the original author and source are credited. 
sulphates and chlorides) and water soluble anionic and cationic polymers which can be used separately or in defined combinations [9-10].

The aim of the study was to evaluate the chemical composition of the biomass from birch wood hydrolysate imitating industrial wastewater and to determine the effectiveness of the isolation of wood biomass from this wastewater with polyethyleneimine (PEI) and compare it with the known and widely used inorganic coagulant.

\section{Materials and methods}

Hydrothermal treatment of $60 \mathrm{~g}$ of sawdust $(<1.00 \mathrm{~mm})$ was performed with $0.04 \% \mathrm{NaOH}$ solution at the hydromodulus $1 / 50$ (mass ratio of the oven dry sawdust to water) and a temperature of $90^{\circ} \mathrm{C}$ for $4 \mathrm{~h}$, using a 5 liter three-neck flask equipped with a return condenser, a thermometer and a stirrer. After hydrolysis the cooled hydrolysate was separated from the treated sawdust by filtration and the obtained biomass was dried to a constant mass, at first, at room temperature and then in an oven at $40^{\circ} \mathrm{C}$. The treated sawdust was washed with distilled water to remove the adsorbed hydrolysed degraded products and dried to a constant mass, at first, at $60^{\circ} \mathrm{C}$ and then in an oven at $105^{\circ} \mathrm{C}$. The characteristics of the treated sawdust and the obtained hydrolysate are represented by their average arithmetic values.

The elemental composition of the sawdust and was determined with the Elementar Analysensysteme GmbH (Germany). Inorganic matter (ash) was found according to Obolenskaya and co-authors [11]. The composition of birch sawdust - lignin, hemicelluloses, cellulose and extractives, before and after hydrolysis, was determined according to analytical chemical procedures. The content of lignin and cellulose was determined by Klason [12] and Kurschner-Hoffer's [13] methods, respectively. The content of hemicelluloses was determined as a difference between the content of holocellulose found by treatment with sodium chlorite and glacial acetic acid and cellulose. The content of extractives represented the sum of the content of the wood substances dissolved in acetone, using a Soxlet extractor, and in boiled water $\left(100^{\circ} \mathrm{C}\right)$ for $3 \mathrm{~h} \mathrm{[11].} \mathrm{The}$ found content of cellulose, lignin, hemicelluloses and extractives in the birch wood residue was the following: $40.3 \%$, $25.2 \%, 29.2 \%$ and $3.9 \%$, respectively. Biomass component composition was identified by Fourier Transform Infrared (FTIR) and Ultraviolet-Visible (UV) spectroscopy. For FTIR- and UV-spectroscop, a spectrophotometer (Perkin-Elmer Spectrum One, USA) with KBr tablets and a UV-VIS Spectrometer GenesysTM 10 (Thermo, USA) were employed.

Monosugars in the hemicelluloses fraction were determined by a high performance liquid chromatography (HPLC) using a liquid chromatograph (LC) SHIMADZU LC-20A (Shimadzu, Tokyo, Japan) with a refraction index detector. HPLC grade acetonitrile (Sigma-Aldrich, Germany) and water (distillated and deionised) was used for the HPLC analysis. Xylose, arabinose, rhamnose, mannose, glucose and galactose were reference standards. The column configuration was an Alltech Platinum Amino column (100 $\mathrm{A} 5 \mathrm{u}, 250 \times 4.6 \mathrm{~mm})$ with a Platinum Amino $\left(\mathrm{NH}_{2}\right)$ guard column $(5 \mathrm{u}, 7.5 \times 4.6 \mathrm{~mm})$. The flow rate was $1.5 \mathrm{ml} / \mathrm{min}$ and the separation was performed at $35^{\circ} \mathrm{C}$. The mobile phase consisted of a degassed filtered mixture of acetonitrile and water $(80: 20 \% \mathrm{v} / \mathrm{v})$. For measuring, a $1.0 \%$ biomass water solution in $0.01 \mathrm{M} \mathrm{NaOH}$ was prepared and filtered through a $0.45 \mu \mathrm{m}$ membrane filter before injection, filled in $1.5 \mathrm{ml}$ bottles with caps and placed in an auto-injector. All samples where tested three times. Z potential of the hydrolysate was measured with Malvern Nanosizer SZ (UK). ${ }^{13} \mathrm{C}$-NMR spectrum of the dried biomass was recorded on a Bruker $300 \mathrm{MHz}$ spectrometer from $150 \mathrm{mg}$ of the sample dissolved in $4 \% \mathrm{NaOD}(1.0 \mathrm{~mL})$.

Polyethyleneimine (PEI, molecular mass of $750 \mathrm{kDa}$ ) (Fluka) and polyaluminium chloride (PACl) (POLYPACS-30, China) $\left(\mathrm{Al}_{2} \mathrm{O}_{3} 30 \%\right.$, basicity $\left.80-85 \%\right)$ was used for the treatment of the hydrolysate for biomass isolation by coagulation. All the coagulation experiments were conducted at a room temperature. The process of coagulation was done by mixing equal volumes of the coagulant and the hydrolysate. After the addition of the coagulant the $\mathrm{pH}$ value of the mixture was adjusted and it was stirred for a period of $1 \mathrm{~min}$ at $200 \mathrm{rpm}$ followed by slow mixing at $40 \mathrm{rpm}$ for $2 \mathrm{~min}$. The effectiveness of coagulation was defined after system settling time of $120 \mathrm{~min}$ and filtration. The residual concentration of biomass and lignin was defined by measuring the obtained filtrate's optical density $(A)$ at 490 and $280 \mathrm{~nm}$ using the previously obtained correlation curves for the biomass and lignin. Chemical oxygen demand (COD), color and permanganate index (PI) for the obtained hydrolysate were determined according to ISO 6060:1989, ISO 7887:1994 and ISO 8467:1993 standards. The efficiency of the model solution purification from total biomass, lignin, reduction of PI and color were calculated by using the following Eqn (1):

$$
\text { removal, } \%=\left[\frac{\left(C_{i}-C_{f}\right)}{C_{i}}\right] * 100
$$

where $C_{i}$ and $C_{f}$ are initial and final concentrations of biomass, lignin, PI and the color.

\section{Results and discussion}

\subsection{Hydrolysate and biomass characteristic}

As shown in Table 1 below, the obtained hydrolysate was characterized by a moderate alkaline $\mathrm{pH}$ value, a low concentration of dry matter, representing the sum of wood degraded products passing to the hydrolysate, a moderate value 
of chemical oxygen demand (COD) and a pronounced color associated with the presence of lignin and lignin-like substances in the hydrolysate.

Table 1. Parameters of the obtained hydrolysate

\begin{tabular}{llllll}
\hline Sample & $\mathrm{pH}$ & $\begin{array}{l}\text { Dry solids, } \\
\mathrm{g} \mathrm{L}^{-1}\end{array}$ & $\begin{array}{l}\text { Density, } \\
\mathrm{kg} \mathrm{m}^{-3}\end{array}$ & $\begin{array}{l}\text { COD, } \\
\mathrm{mg} \mathrm{O} \mathrm{L}^{-1}\end{array}$ & $\begin{array}{l}\text { Colour, } \\
\mathrm{mg} \mathrm{Pt} \mathrm{L}^{-1}\end{array}$ \\
\hline Hydrolysate & 9.02 & 1400 & 0.998 & 1285 & 746 \\
\hline
\end{tabular}

The average yield of the solid biomass from the hydrolysate was $7.1 \pm 0.2 \%$ relative to the initial sawdust mass. The yield calculated from the sawdust mass loss was a little higher than from the dried biomass which may be associated with a partial adsorption of the formed degraded wood products at the sawdust surface. The defined elemental composition of the dried biomass was the following: $37.75 \% \mathrm{C} ; 4.78 \% \mathrm{H} ; 56.69 \% \mathrm{O} ; 0.30 \% \mathrm{~N} ; 0.14 \% \mathrm{~S}, 0.34 \%$ of inorganic matter. A SEM image (Fig. 1) characterized the obtained lignocellulosic biomass as an amorphous one without pronounced morphological features.

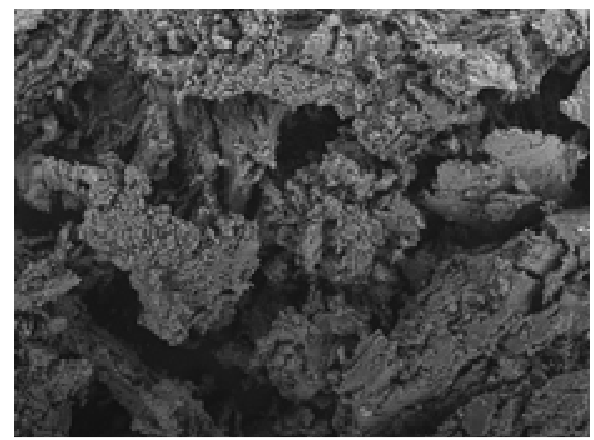

Fig. 1. SEM image of the biomass

The biomass had an enhanced ratio of $\mathrm{O} / \mathrm{C}$ close to $1.5 \pm 0.1$ that indicated the presence of a substantial amount of oxygen-containing groups including hydroxyl, carbonyl and carboxyl groups in the hydrolysed wood products. The zeta potential value of the hydrolysate close to $-30 \mathrm{mv}$ testified the high content of these groups in the biomass. With decreasing $\mathrm{pH}$ to 2.0 , the $\mathrm{Z}$ potential value of the hydrolysate fell to $-10 \mathrm{mv}$, reflecting the decrease in the ionisation degree of the hydroxyl and carboxyl groups in lignin and hemicelluloses fragments.

For fuller characterisation of the chemical composition of the biomass, the FT-IR and UV spectroscopy were applied. The interpretation of the obtained results was based on the literature data concerning the studies of lignin and hemicelluloses by the methods [14-16].

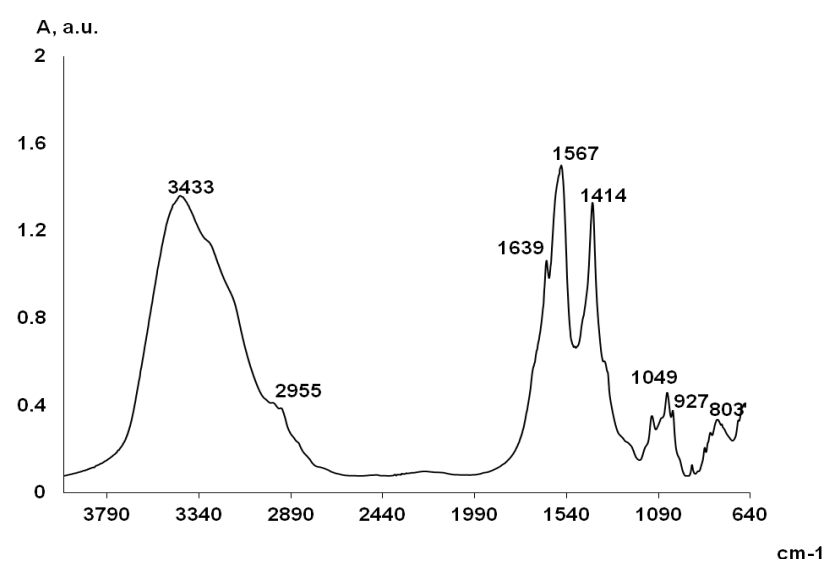

Fig. 2. FT-IR spectrum of the biomass

According to the FT-IR spectrum of the biomass (Fig. 2) the strong broad band at $3433 \mathrm{~cm}^{-1}$ is attributed to both aromatic and aliphatic hydroxyl groups. The band at $2955 \mathrm{~cm}^{-1}$ is caused by $\mathrm{C}-\mathrm{H}$ stretch vibrations in the methoxyl, methyl and methylene groups present in the aromatic and saccharide structures of the hydrolysed products. The narrow bands at $1639 \mathrm{~cm}^{-1}$ and $1567 \mathrm{~cm}^{-1}$ may be assigned to the presence of ketones, carbonyls and ester groups in the biomass lignin and hemicelluloses. At the same time, in the spectrum, the pronounced bands corresponding to the aromatic skeletal vibrations of lignin structures, namely, $1600 \mathrm{~cm}^{-1}$ and $1505 \mathrm{~cm}^{-1}$ [17] are absent. The presence of lignin structures in the biomass is testified by the absorbance at $1414 \mathrm{~cm}^{-1}$, assigned to skeletal vibrations and $\mathrm{C}=\mathrm{O}$ group stretching in the syringyl and 
guaiacyl aromatic rings. The $\mathrm{CH}_{2}$ deformation vibrations appear at $1351 \mathrm{~cm}^{-1}$ and may be caused by both lignin and hemicelluloses structures. The bands in the region of $1115-803 \mathrm{~cm}^{-1}$ are typical for hemicelluloses. This region contains $\mathrm{C}-\mathrm{C}$ ring vibrations, overlapped with the stretching vibrations of $\mathrm{C}-\mathrm{OH}$ side groups and the $\mathrm{C}-\mathrm{O}-\mathrm{C}$ glucosidic band vibrations. The band at $1115 \mathrm{~cm}^{-1}$ may be caused by the presence of pectin. The band at $1047 \mathrm{~cm}^{-1}$ is attributed to the C-O-C stretching in glucosidic linkages, which is typical for xylan. The small bands at $927 \mathrm{~cm}^{-1}$ and $803 \mathrm{~cm}^{-1}$ are characteristic of the $\beta$-glucosidic bonds between the sugars units.

The obtained UV spectra testify the presence of aromatic fragments in the biomass, namely, the absorption at $280 \mathrm{~nm}$ is typical for lignin. At the same time, the relatively low value of the calculated extinction coefficient $\left(3.891 \mathrm{~g}^{-1} \mathrm{~cm}^{-1}\right)$ at this band indicates the dominant content of the non-aromatic structure in the dried biomass.

The chemical and morphological characteristics of the precipitated birch lignin were studied by Shulga and co-authors [18]. Hemicelluloses in the biomass were identified by a liquid chromatograph. The identifying HPLC analysis (Fig. 3) testified the presence of xylose, mannose, arabinose, rhamnose and glucose monomers in a $1.0 \%$ birch hydrolysate.

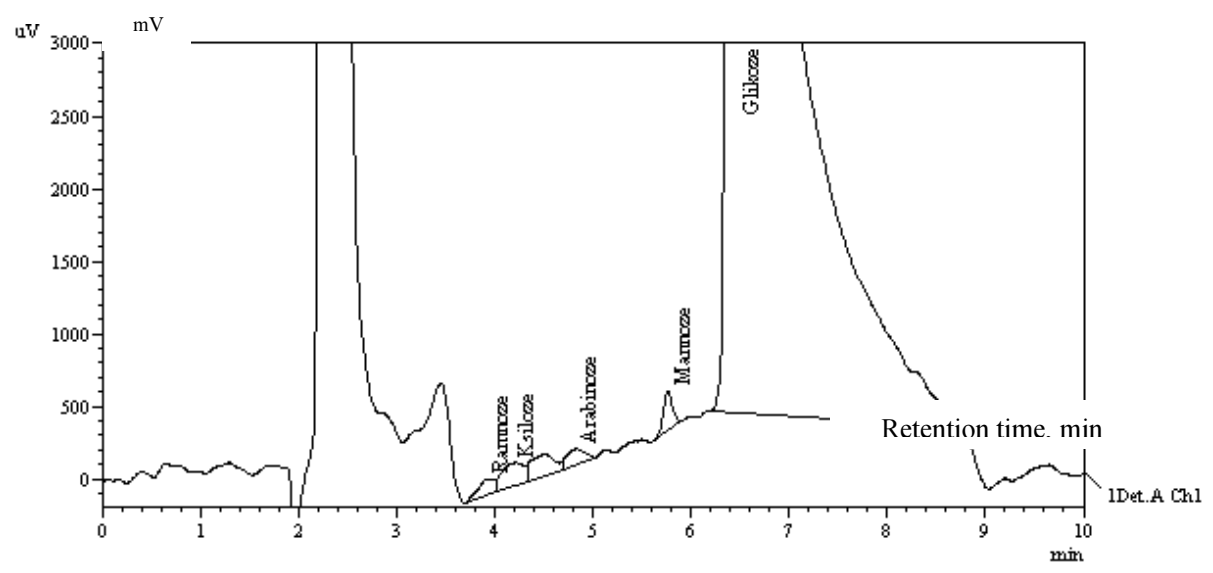

Fig. 3. HLPC chromatogram of a $1 \%$ biomass aqueous solution in $0.01 \mathrm{M} \mathrm{NaOH}$

The obtained quantitative data analysis indicated that the content of the first four sugars in the obtained hydrolysate was comparatively low and did not exceed $0.1 \%$. This means that the hemicelluloses in the hydrolysate are represented mainly by polysaccharides. At the same time, the glucose content in the hydrolysate was higher and was close to $0.4 \%$, which may be associated with the features of the birch lignocellulosic matrix degradation during the hydrolysis.

For obtaining more detailed information about hemicelluloses in the hydrolysate, the ${ }^{13} \mathrm{C}$-NMR method was applied. The ${ }^{13} \mathrm{C}-\mathrm{NMR}$ spectra (Fig. 4) demonstrates five pronounced signals at 102.3, 75.9, 73.7, 73.3 and 63.3 ppm, assigned to C-1, C4, C-3, C-2 and C-5 of $\beta$-D-xylopyranoside units. The signal at $23.3 \mathrm{ppm}$ may be assigned to carbon atoms in lignin methoxyl groups. The two signals observed at 56.02 and $168.4 \mathrm{ppm}$ may be assigned to methoxyl groups in the lignins' aromatic rings and the carboxyl group of glucuronic acid, respectively. The signals at $74.8-75.9$ ppm may be assigned to $\mathrm{C} 3$ in $\beta$-D-glucose and C5 in $\beta$-mannose. The shift at 118.7-119.7 ppm can be attributed to the presence of an ester bond between the carboxyl group of D-glucuronic acid and phenylpropan side chains of lignin. The signal at 129.4 ppm may be assigned to carbon atoms in the p-substituted lignin aromatic ring.

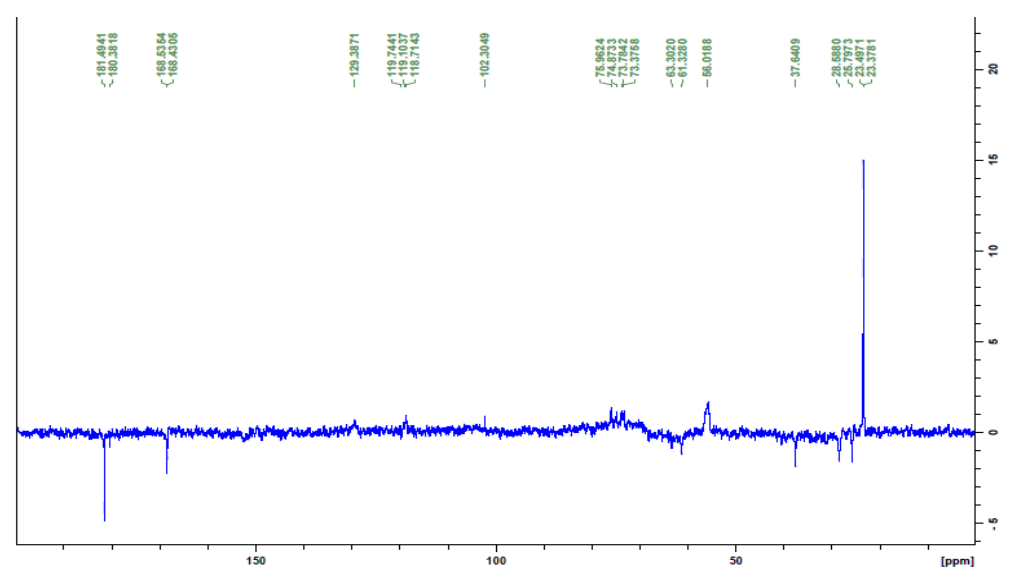

Fig. 4. 13C CMR spectrum of the dried biomass

To fractionate the lignocellulosic biomass and calculate the content of lignin and hemicelluloses therein, the precipitation of the hydrolysate with concentrated sulphuric acid with the following treatment of the formed filtrate with ethanol according to Liu and co-authors [19] was employed. The scheme of the applied fractionation is given in Fig. 5. 


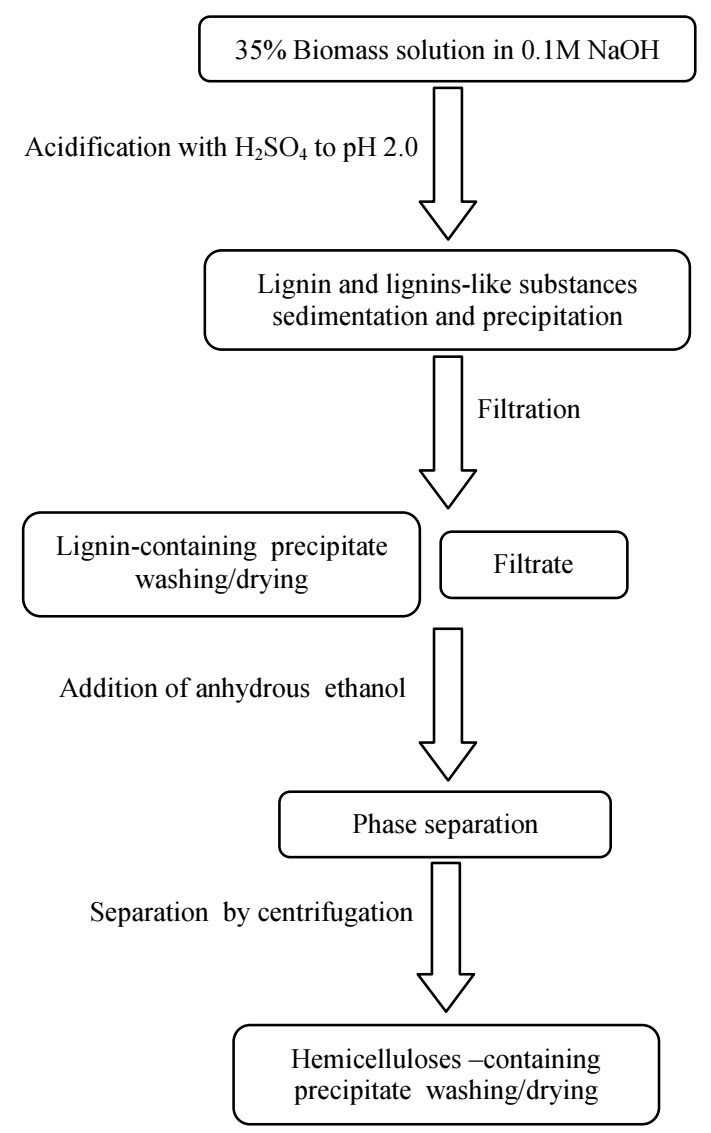

Fig. 5. Scheme of biomass fractionation

For the fractionation the biomass dried at room temperature was dissolved in $0.1 \mathrm{M} \mathrm{NaOH}$ for obtaining $50 \mathrm{ml}$ of a $35 \%$ biomass solution. The concentrated hydrolysate was, at first, acidified with $20 \%$ sulphuric acid to a pH of 2.0 at room temperature with the following filtration and centrifugation of the obtained suspension for separating the lignin-containing fraction. The lignin precipitate was washed with distilled water to $\mathrm{pH} 5.5$ and dried in an oven at $40^{\circ} \mathrm{C}$. Anhydrous ethanol was added to the obtained filtrate at the volumetric ratio of ethanol/filtrate close to 4 . After addition of anhydrous ethanol, the hemicelluloses-containing fraction precipitated and then was isolated by centrifugation, washed with the ethanol and dried in an oven at $40^{\circ} \mathrm{C}$. The content of hemicelluloses- and lignin-containing fractions in the biomass was assessed from the masses of the obtained dried precipitates.

The obtained results of the biomass fractionation showed that the content of the lignin and hemicelluloses fractions in the solid biomass corresponded to $13.5 \%$ and $75.2 \%$, respectively. At the same time, the low molecular products of the lignocellulosic matrix destruction that were not able to be precipitated by this procedure occupied $11.3 \%$ of the solid biomass. The measuring of the content of water-soluble lignin [11] in the filtrate obtained after the Klason lignin [12] extraction corresponded to $5.89 \%$, and the total content of lignin (Klason and water-soluble) in the biomass was $10.9 \%$. As the obtained results have shown, the content of lignin, hemicelluloses and water-soluble degraded wood products in the solid biomass corresponded to the following mass ratio: 1.2/6.7/1.0, respectively.

Table 2. Wood component composition of birch sawdust before and after the hydrolysis

\begin{tabular}{lllll}
\hline Sample & $\begin{array}{l}\text { Holocellulose, } \\
\%\end{array}$ & $\begin{array}{l}\text { Cellulose, } \\
\%\end{array}$ & $\begin{array}{l}\text { Hemicellulose } \\
\%\end{array}$ & $\begin{array}{l}\text { Lignin, } \\
\%\end{array}$ \\
\hline Untreated & 68.5 & 40.3 & 28.2 & 25.2 \\
Treated & 70.4 & 46.8 & 23.6 & 25.1 \\
\hline
\end{tabular}

Simultaneously, the changes in the wood composition of birch sawdust due to its hydrolysis were assessed. According to the results listed in Table 2 the main changes in the wood composition caused by the hydrolysis took place for cellulose, i.e., its content increased by $6.5 \%$ and hemicelluloses, i.e., their content decreased by $5.6 \%$, while the content of lignin diminished by only $0.1 \%$. It is reasonable to assume that the gain in the cellulose content and the negligible alteration in the lignin content in the pre-treated lignocellulosic matrix were associated with the notable losses of hemicelluloses and watersoluble extractives during the hydrothermal treatment. 


\subsection{Isolation of the biomass by coagulation}

Polyethyleneimine (PEI) was selected as a coagulant for isolation of the biomass from model woodworking wastewater. Polyethyleneimines are highly branched polymers with primary, secondary and tertiary amine groups which behave like cationic polyelectrolytes because the amine groups are partially protonated in acidic and neutral $\mathrm{pH}$ conditions.

In coagulation-flocculation processes, coagulant dosage and $\mathrm{pH}$ plays an important role in determining the coagulation efficiency. Optimal conditions of biomass coagulation from the hydrolysate were searched in a PEI dosage range of 7$140 \mathrm{mg} / \mathrm{l}$ and in a pH interval of 3-10. Figure 6 clearly indicates that PEI coagulation efficiency highly depends on pH and dosage. Total biomass and lignin removal and PI reduction efficiencies increase with increase in coagulant dosage and $\mathrm{pH}$ until it reaches its highest value, optimum $\mathrm{pH}$, after which the removal and reduction efficiencies start to decrease. The optimum dosage is $35 \mathrm{mg} / \mathrm{L}$ and the optimum $\mathrm{pH}$ is approximately 6.0. At the optimum PEI dosage and $\mathrm{pH}$ up to $93 \%$ $(1302 \mathrm{mg} / \mathrm{L})$ of total biomass, $64 \%$ of lignin, $90 \%$ of color and $57 \%$ of PI was reduced.

For comparison one of the most widely used inorganic coagulant polyaluminium chloride (PACl) was selected. $\mathrm{PACl}$ and its analogues are considered to be the most effective coagulants in high color wastewater treatment [20-21]. It was determined that the optimum PACl dosage and $\mathrm{pH}$ are $100 \mathrm{mg} / \mathrm{L}$ and 6.0 , respectively. This result reveals that the optimum coagulant dosage for PEI is 2.8 times lower than that of PACl but the optimum $\mathrm{pH}$ for both coagulants remains the same at $\mathrm{pH}$ 6.0. The extraction of the total biomass with $\mathrm{PACl}$ is $80 \%$, and that of lignin is $53 \%$ while these values for PEI are higher, namely, $93 \%$ and $64 \%$ (Fig. 7). PEI is characterised by higher indices of the removal of total biomass and lignin, as well as color and PI at the lower application dose than that for the PACl.

The higher efficiency of the PEI as a coagulant may be governed by realising the hybrid mechanism of the biomass components' precipitation which includes their coagulation, following the pattern of charge neutralisation, and its flocculation, following the pattern of bridge formation, taking into account its high molecular mass, in contrast to PACl, which precipitates the biomass mainly according to the heterocoagulation mechanism. This is favoured by the high density of the charge of PEI macromolecules, its branching, and the high molecular mass. At the same time, the moderate values of a PI reduction for both PEI and PACl may indicate the presence of an essential content of low-molecular products of the hydrolysed lignocellulose that are not possible to extract with these coagulants, and additional post-treatment of the hydrolysate after its coagulation is needed.

(a)

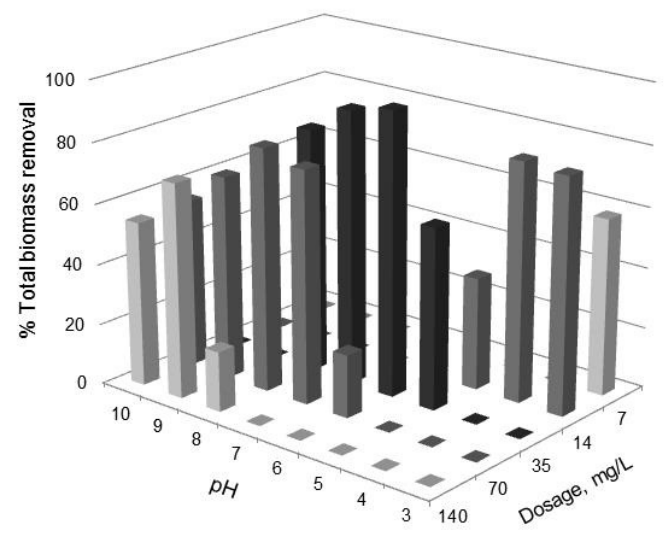

(b)

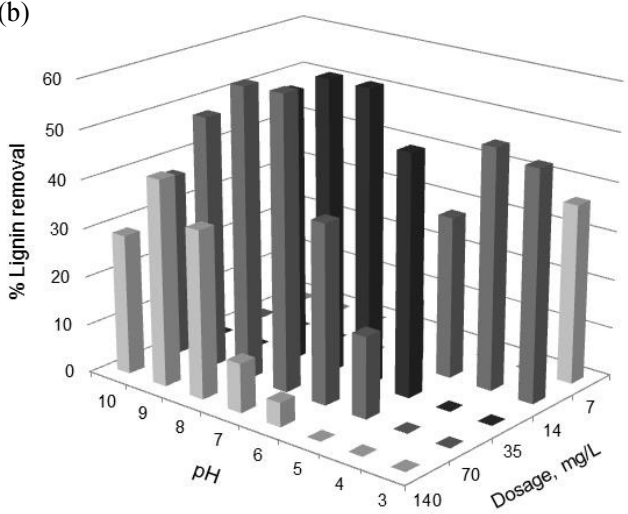

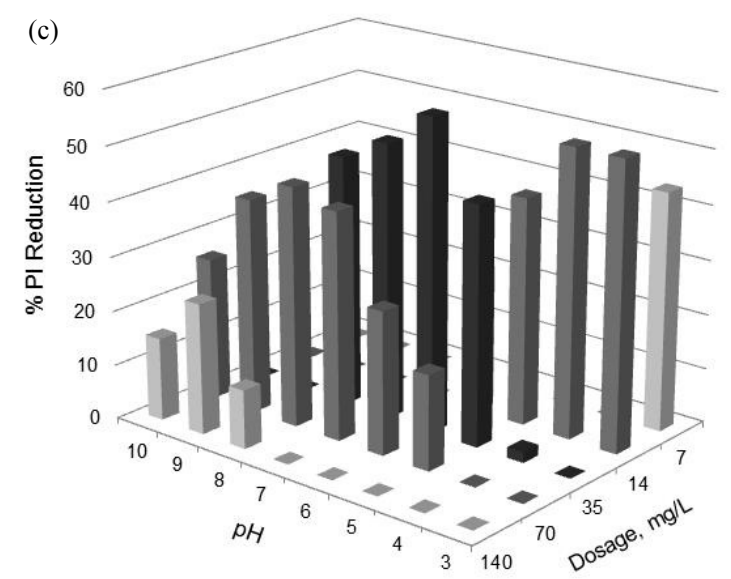

Fig. 6. Effects of PEI dosage and $\mathrm{pH}$ on (a) total biomass removal, (b) lignin removal and (c) PI reduction 


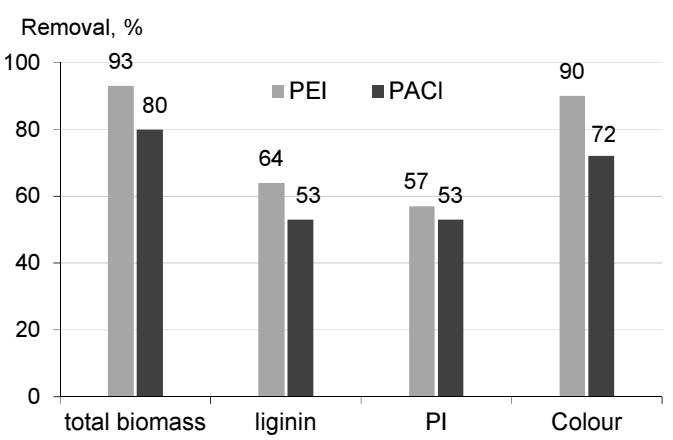

Fig. 7. Comparison of total biomass, lignin, $\mathrm{PI}$ and colour removal for $\mathrm{PEI}$ and $\mathrm{PACl}$ at optimal coagulant dosage and $\mathrm{pH}$

\section{Conclusion}

For imitating woodworking wastewater, birch sawdust was hydrothermally treated in mild alkaline conditions at $90^{\circ} \mathrm{C}$. The yield of the solid biomass did not exceed $7 \%$ and contained mainly hemicelluloses in the polysaccharide form and lignin. The applied instrumental analysis (FTIR-, UV- spectroscopy) testify the dominant content of hemicelluloses in the obtained biomass. The study of the biomass with a high performance liquid chromatograph identified, along with xylose, glucose and mannose, also arabinose and rhamnose. The fractionation of the biomass was performed using concentrated sulphuric acid and ethanol. As the obtained results have shown, the content of lignin, hemicelluloses and water-soluble degraded wood products in the solid biomass corresponded to the following mass ratio: $1.2 / 6.7 / 1.0$, respectively.

PEI is characterized by higher indices of the removal of total biomass $(93 \%, 1302 \mathrm{mg} / \mathrm{L})$ and lignin $(64 \%)$, as well as color (90\%) and PI (57\%), at the application dose 2.8 times lower than that for PACl. The higher efficiency of PEI as a precipitant may be governed by realizing the hybrid mechanism of the biomass extraction which includes its coagulation following the pattern of charge neutralization and its flocculation following the pattern of bridge formation in contrast to $\mathrm{PACl}$, precipitating biomass mainly according to the heterocoagulation mechanism. This is favored by the high density of the charge of PEI macromolecules, its branching, and the high molecular mass.

\section{Acknowledgements}

The authors are grateful to the Latvian Council of Science and the Latvian Ministry of Economics for the financial support of the National Research Programme VPP-5. The authors also gratefully acknowledge the experimental support of Dr. V. Rjabovs at Riga Technical University.

\section{References}

[1] Brodeur, G.; Yau, E.; Badal, K. J.; Collier, J.; Ramachandran, B.; Ramakrishnan, S. 2011. Chemical and physicochemical pretreatment of lignocellulosic biomass: a review, Enzyme Res. 2011: Article ID 787532: 17.

[2] Mtui, G.Y.S. 2009. Recent advances in pretreatment of lignocellulosic wastes and production of value added products, African J. Biotechnol. 8(8): 1398-1415.

[3] Yang, B.; Wyman, C. E. 2008. Pretreatment: the key to unlocking low-cost cellulosic ethanol, Biofuel. Bioprod. Bior. 2: 26-40. http://dx.doi.org/10.1002/bbb.49

[4] Permission of polluting activities for B category Nr. RE12IB0006. 2012. Rezekne Regional Environmental Governance, Ltd RSEZ Verems: 82.

[5] Fengel, D.; Wegener, G. 1984. Wood-Chemistry, Ultrastructure, Reactions. Berlin, New York: Walter de Gruyter. 613 p.

[6] Lakhdar, A.; Scelza, R.; Scotti, R.; Rao, M.A.; Jedidi, N.; Gianfreda, L.; Abdelly, C. 2010. The effect of compost and sewage sludge on soil biologic activities in salt affected soil, R.C. Suelo Nutr. Veg. 10(1): 40-47. http://dx.doi.org/10.4067/S0718-27912010000100005

[7] Lin, D.F.; Weng, C.H. 2001. Use of sewage sludge ash as brick material, J. Environ. Eng. 127(10): 922-928. http://dx.doi.org/10.1061/(ASCE)0733-9372(2001)127:10(922)

[8] Rio, S.; Le Coq, L.; Faur, C.; Le Cloirec, P. 2006. Production of porous carbonaceous adsorbent from physical activation of sewage sludge: application to wastewater treatment, Water Sci. Technol. 53(3): 237-244. http://dx.doi.org/10.2166/wst.2006.102

[9] Bratby, J. 2007. Coagulation and flocculation in water and wastewater treatment. 2nd ed. London, Seattle: IWA Publishing.

[10] Bolto, B.; Gregory, J. 2007. Organic polyelectrolytes in water treatment, Water Res. 41(11): 2301-2324. http://dx.doi.org/10.1016/j.watres.2007.03.012

[11] Obolenskaya, A.V.; Elnitskay, Z. P.; Leonovich, A. A. 1991. Laboratory Manual on Wood and Cellulose Chemistry. Moscow: Ecologia.

[12] Dence, C. W. 1992. The determination of lignin. In: Methods of Lignin Chemistry. Eds. Lin S.Y., Dence C.W. Berlin: Springer-Verlag.

[13] Browning, B. L. 1967. Methods of Wood Chemistry. Vol. 2. New York, London: Intersci. Publ.

[14] Sanchez, S.; Egues, I.; Llano-Ponte, R.; Labidi, J. 2011. Acid- and base- catalized hydrolyses of corn stalk, Bioresources 6(2): $1830-1842$.

[15] Fang, J. M.; Sun, R. C.; Tomkinson, J. 2000. Isolation and characterisation of hemicelluloses and cellulose from rye straw by alkaline peroxide extraction, Cellulose 7(1): 87-107. http://dx.doi.org/10.1023/A:1009245100275

[16] Kacurakova, M.; Capek, P.; Sasinkova, V.; Wellner, N.; Ebringerova, A. 2000. FT-IR study of plant cell wall model compounds: pectic polysaccharides and hemicelluloses, Carbohyd. Polym. 43: 195-203. http://dx.doi.org/10.1016/S0144-8617(00)00151-X

[17] Faix, O. 1992. Fourier Transform Infrared Spectroscopy. In: Methods in Lignin Chemistry. Eds. Lin S. Y., Dence C.W. Berlin: Springer-Verlag.

[18] Shulga, G.; Vitolina, S.; Shakels, V.; Belkova, L.; Cazacu, G.; Vasile, C.; Nita, L. 2012. Lignin separated from the hydrolyzate of hydrothermal treatment of birch wood and its surface properties, Cellulose Chem. Technol. 46(5-6): 307-318.

[19] Liu, Z.; Ni, Y.; Fatehi, P.; Saeed, A. 2011. Isolation and cationization of hemicelluloses from pre-hydrolysis liquor of kraft-based dissolving pulp production process, Biomass Bioenerg. 35: 1789-1796. http://dx.doi.org/10.1016/j.biombioe.2011.01.008

[20] Duan, J.; Gregory, J. 2003. Coagulation by hrdrolysing metal salts, Adv. Colloid Interf. 100-102: 475-502. http://dx.doi.org/10.1016/S0001-8686(02)00067-2

[21] Brovkina, J.; Shulga, G.; Ozolins, J. 2011. Coagulation of Wood Pollutants from Model Wastewater by Aluminium Salts, in Proc. of the 8th International Scientific and Practical Conference "Environment. Technology. Resources", Latvija, Rezekne, 2011. 63-67. 